\title{
Religiosity and Condom Use with Casual Sex Partners in Ghana
}

Authors: D.M. Badasu, S.O. Kwankye, O.A. Sanuade, A. El-Adas and K. Atuahene Affiliations: Regional Institute for Population Studies, University of Ghana, Legon (Badasu); Regional Institute for Population Studies, University of Ghana, Legon (Kwankye); Regional Institute for Population Studies, University of Ghana, Legon (Sanuade); Ghana AIDS Commission, Accra, Ghana (El- Adas); Ghana AIDS Commission, Accra, Ghana (Atuahene) Corresponding author: S.O. Kwankye, Regional Institute for Population Studies, University of Ghana, Legon; email: skwankye@ug.edu.gh; kwankyeso@yahoo.co.uk

\begin{abstract}
Level of religiosity is an indicator of the degree of involvement of people in religious beliefs/activities and a measure of attitudes to sexual-related activities, such as casual sex or using condoms to avert unplanned pregnancy or sexually transmitted infections. This paper uses nationally representative cross-sectional data collected in 2011/2012 to examine the relationship between religiosity and the likelihood of engaging in casual sex and condom use in Ghana. A sample of 4,168 males and females was used to assess sexual activities and condom use with casual sexual partner using binary logistic regression analysis. The study was based on the Reference Group Theory which suggests that religious teachings often dictate the sexual behaviors/attitudes of individuals and was informed by the fact that most conventional religions discourage pre-marital sex and adultery. The study examined how religiosity expressed by individuals impacts casual sex, which is considered a form of adultery. An attempt was made to discover if religiosity impacts condom use as a form of protection against HIV and other sexually transmitted infections and unplanned pregnancy. The results indicate that persons who attend religious meetings more than once a week are less likely to have a casual sexual partner compared to others who attend occasionally or less frequently. No differences between groups with lower level of religiosity are apparent. The level of religiosity did not affect condom use among those who have sex, when other variables are controlled for. Differences in age, sex, level of education, rural/urban residency and marital status are statistically related to condom use with a casual sex partner. The paper concludes that condom use with a casual sex partner may not largely depend on how religious or otherwise one may be, but rather on the individual's risk perception based on a person's socioeconomic status, particularly with respect to a person's level of education.
\end{abstract}

\section{Keywords}

Religiosity, condom use, casual sex, HIV, AIDS, Ghana 


\section{Introduction}

In the absence of abstention male and female condoms are the only preventive methods against HIV infection among sexually active persons. According to the Ghana AIDS Commission (2015), the HIV Sentinel Survey showed that median HIV prevalence among persons 15-49 years in Ghana declined to an estimated 1.6 percent in 2014 (down from 3.6 percent in 2003) during a period when the estimated adult national HIV prevalence was at 1.47 percent. The Commission reported further that the proportion of persons 15-49 years who had an HIV test in the past 12 months and knew the results was 6.8 percent for females and 4.1 percent for males. In addition to HIV prevention, accurate use of condoms has been shown to protect against unwanted or unintended pregnancy. Yet, there is low use of condoms in Ghana. For example, the results of the 2008 Ghana Demographic and Health Survey (GDHS) show that only $20.2 \%$ of all women and $19.4 \%$ of all married women aged 15-49 years have ever had intercourse with a male partner who wore a condom (Ghana Statistical Service et al. 2009). The 2014 GDHS did not report on ever use of condoms, but reported current condom use of the male condom at 1.2 percent among currently married women in Ghana and zero percent for the female condom (Ghana Statistical Service et al. 2015). This compares with the United Nations (2015) estimates of contraceptive prevalence by method among married or in-union women (15-49 years), which reports percent male condom use at 35.8 percent for Botswana, 1.9 percent for Burkina Faso, 14.8 percent for Canada, 2.1 percent for Cote d'Ivoire, 2.5 percent for Nigeria, 21.9 percent for Swaziland and 11.6 percent for the United States of America. As reported in the 2014 GDHS, the proportion of the sexually active population that uses any contraception in Ghana is 26.7 percent among currently married women.

The generally low reported prevalence rate of condom (and other contraceptive devices) use in Ghana, particularly among married men and women, has been attributed mainly to a sociocultural environment that cherishes large family size. This perception persists despite the high knowledge of the benefits of family planning among sexually active people in terms of promoting the health of the mother and child. Also, myths and misconceptions about family planning abound in Ghanaian society. Many people in Ghana think erroneously that family planning is only meant to control childbearing among women. Family planning is considered by some sections of the population to be synonymous with sexual promiscuity, especially when young people are involved. 
A few studies have reported misconceptions about family planning and contraceptive use in Ghana. For example, Kwankye (2007) and Nabila et al (1999) reported that continuous contraceptive use is perceived among some Ghanaians as a cause of sterility, especially among young persons. They further indicated that some of the misconceptions are even reduced to the absurdity that condoms can enter the womb of the woman when used. Religious reasons have also been associated with the non-use of modern contraceptives, including condom use, particularly among Catholics.

Religiosity can cause differences in people's sexuality and is an important factor in assessing people's vulnerability to HIV and AIDS (see Regnerus, 2007). Studies have shown that religiosity determines people's attitude toward sex and influences sexual decision-making and behaviour (Brewster, Cooksey, Guilkey and Rindfuss, 1998; Rostosky et al. 2004; Lefkowitz et al. 2010). Religiosity may help delay sexual debut but may affect contraceptive use negatively (Rostosky et al. 2004; Meier 2003; Rizzi 2004). On the other hand, people who are religious may have lower knowledge about sexual and reproductive health issues compared to those who are non-religious (Regnerus 2005). This is because religiosity discourages conversation about sexuality, which may have implications on the relevant information available to those who are religious (Regnerus 2005).

Religious norms may also reject the use of artificial family planning methods. This means that the use of condoms among those who are religious may be lower than that of their counterparts who are not religious (Zaleski and Schiaffino 2000). In addition, those who are religious may be less likely to cognitively plan their sexual encounters and so have lower likelihood of condom use during sexual intercourse (Ladin L'Engle, Jackson and Brown 2006). Basically, studies have shown that the impact of religiosity on sexual behavior can delay the onset of sexual debut or reduce the likelihood of contraceptive usage (Rostosky et al., 2004; Lefkowitz et al. 2010; Chimbindi et al. 2010).

In general, the people of Ghana are very religious. Almost everyone is considered to belong to one religion or another (Böhmig 2010). From the 2010 Population and Housing Census, only $5.3 \%$ of the population was recorded to have no religious affiliation (Ghana Statistical Service 2013). Yet, not all people who profess one religious faith or another actually practise their religious dictates all the time and may even swap religions they may not profess to, especially in times of critical need (Atiemo 2013; Anarfi and Gyasi- Gyamerah 2015). Religious affiliation 
alone, therefore, may be misleading in understanding the possible effects of one's religious affiliation on condom use, which is a major reproductive health behavior at the individual level in the context of HIV and AIDS in Ghana. This study, therefore, focuses on examining how a person's religiosity rather than religious affiliation relates to condom use in Ghana. Religiosity is used to describe the frequency at which one attends religious meetings and not necessarily mere affiliation or profession.

According to the Reference Group Theory, individuals' religious teachings tend to dictate their sexual behaviors and attitudes (Penhollow, Young and Denny 2005). Following this line of thought, this study postulates that the more an individual is influenced by the teachings of the religion he/she is affiliated with, the more he/she will be actively involved in the activities of that religion, and consequently, become religious. Since most conventional religions discourage pre-marital sex and adultery (Penhollow, Young and Denny 2005) it is important to examine how individuals who demonstrate religiosity are involved in casual sex, which is considered a form of adultery and or infidelity. Relatedly, it is important to examine if such individuals use condoms to protect themselves against HIV infection and unplanned pregnancy. An understanding of the role that religiosity plays in mediating the use of condoms during a casual sexual encounter is important in terms of formulating condom use strategies and associated advocacy within highly religious societies in the era of HIV and AIDS.

\section{Methodology}

\section{Sample selection}

This study was part of a bigger study that used quantitative and qualitative methods of data collection. The quantitative approach involved the selection of a representative sample of respondents from all 10 regions in Ghana. The sample selection took place as follows.

Data from the 2000 Census Enumeration Areas (EAs) were used as the sampling frame for the selection of EAs and households in each of the 10 administrative regions. This was done because the 2010 EA Sampling Frame was not accessible at the time of the survey. The study was, however, mindful of the challenges associated with the use of the 2000 Population and Housing Survey (PHC).

The study was conducted in Ghana in all 10 regions in the country: Western, Central, GreaterAccra, Volta, Eastern, Ashanti, Brong-Ahafo, Northern, Upper East and Upper West. Male and 
female respondents age 12-49 and 12-59 years respectively - people most likely to be sexually active - were selected from households in urban/rural EAs in Ghana. The EAs were stratified by region and by rural and urban areas, and then selected proportionally to the number of households in each region so that regions with a large number of households had more EAs selected compared to others with fewer households. Training of field enumerators and their supervisors was conducted between 29 July 2011 and 3 August 2011. A household listing exercise was undertaken in all of the selected EAs in the 10 regions to determine the number of eligible persons in each household, which provided an effective basis for the selection and interview of eligible respondents in the quantitative survey in each selected EA.

A sample of 3,200 households was randomly selected after the household listing exercise for the survey of females 12-49 years and males 12-59 years in all 10 regions in Ghana. The systematic sampling was conducted by first selecting 30 households each with an eligible female 12-49 years from each EA. In each EA, 30 households were selected. The selection was by systematic sampling procedure. This was done by dividing the number of eligible households listed in the EA by 30 to determine the systematic selection interval for the selection of the required number of households (i.e. 30) after choosing a random start number. From each selected household, all eligible males 12-59 years and females 12-49 years were interviewed. The choice of the upper limits of the age groups was done to conform with the Demographic and Health Survey (DHS) convention of targeting females of reproductive ages 15-49 years and males 1559 years. On the other hand, the minimum age of 12 years was used to conform to the 2010 Population and Housing Census of Ghana that put the minimum age at sexual activity and reproduction at 12 years to capture possible reproductive health behaviors and practices below 15 years of age. In the analysis, however, males 50-59 years were excluded in order to make them comparable to the females whose ages did not go beyond 49 years.

A total of 107 EAs were randomly selected nationwide from the stratified EAs by region and rural/urban places of enumeration in order to attain a sample of 3,200 households. Selecting at random 30 households from each of the 107 EAs, however, increased the total number of households to 3,210. On the assumption that each household would contain at least one eligible woman, we hoped to achieve a female individual sample of at least 3,210 throughout Ghana to be used in the analysis. For every household that was selected with an eligible woman, all eligible men in that household were to be interviewed in addition to all other eligible women present in 
the household at the time the interviewers called on each of the households. In the field, however, enumerators reported enumerating one eligible male in each household in addition to all the eligible women. At the end of the survey, a total of 6,027 respondents were interviewed, comprised of 2,074 males and 3,953 females.

A non-response rate of 3.5 percent was estimated for the survey of respondents. The interviewers were asked to replace any non-response case with another respondent by going through the same process of systematic random selection of respondents. The survey, therefore, was able to achieve the target number of households that resulted in the overall number of male and female respondents for the study.

\section{Data analysis}

The data analysis was limited to those who were sexually active. Hence, a total of 4,168 formed the sample size for the study. The dependent variable was condom use (male and female condoms) with a casual sexual partner. The responses were coded "1" if the condom was used with a casual sexual partner and "0" if otherwise. A casual sexual partner refers to a person who is not a regular, permanent or long-term sexual partner. Such a sexual partner is different from marital partners (e.g. husband or wife) or persons who are cohabiting, living together or in a consensual sexual union. In many cases, a sexual encounter with a casual partner may take place only once and may never be repeated.

Descriptive statistics were used to present the socio-demographic characteristics of the respondents. Binary logistic regression was used to examine the relationship between religiosity and condom use with a casual sexual partner. Two levels of analysis were undertaken to examine the relationship between religiosity and condom use with a casual sexual partner. In the first analysis, binary logistic regression analysis was used to estimate the role of level of religiosity on the likelihood of having casual sex. In the second analysis the relationship between religiosity and condom use was carried out focusing on respondents who had ever had a casual sexual encounter prior to the survey, controlling for the socio-demographic characteristics of the respondents. In both situations, the analysis sought to find out which of the variables that were controlled for affected the likelihood of having a casual sexual partner or using condoms during a sexual encounter with a casual sexual partner. The stepwise method of regression analysis was, therefore, used to disentangle the role of each background variable involved in explaining either 
having a casual sexual partner or using condoms with a casual sexual partner.

\section{Ethical considerations}

The research instruments/protocols were presented to the Noguchi Institute for Medical Research's Ethical Review Committee and secured ethical approval before the commencement of the study. In addition to the research instruments/protocols, informed consent statements were developed for various categories of respondents that took care of all categories of respondents for the study, including adult males and females as well as minors below age 18 years for whom parental consent was sought before their participation in the study. The respondents were assured in the informed consent statement that the confidentiality of the information that they provided would be guaranteed by ensuring that their names and individual characteristics would not be included in any report or publication.

\section{Results}

\section{Background characteristics}

The background characteristics of the respondents are shown in Table 1 (see Annex 1 to the present document). As can be seen from Table 1, a higher proportion of the respondents was made up of females (71.0\%). More than one-fifth (27.0\%) had no education, about 8 percent had higher education and one in every three $(33.2 \%)$ had middle/JHS education. The mean age was $31.6 \pm 8.8$ years. About one-fourth $(24.4 \%)$ were $12-24$ years and roughly 20 percent were $25-29$ years. The respondents were split almost evenly between rural and urban areas of residence. In terms of religious affiliations, more than three- quarters (77.2\%) were Christians, less than onefifth (17.8\%) were Muslims and about 5 percent (4.9\%) belonged to traditionalist/spiritual/other religions. Among Christians, the highest proportion (42.3\%) was among Charismatic/Pentecostal adherents. More than 4 in every $10(43.2 \%)$ were Akan while, the Guan reported the least proportion of about 4 percent of the total number of respondents. Table 1 further shows that a high proportion of the respondents $(62.5 \%)$ were currently married.

Regarding religiosity, 40.8 percent attended religious meetings once a week and 43.0 percent attended more than once a week. The same proportion of about 2 percent of the total number of respondents each attended religious meetings every two weeks and once a month, and 12.3 percent attended religious meetings occasionally. With regard to casual sexual partnership,

slightly more than one-fifth of the respondents (20.7\%) had a casual sexual partner. Among those 
that had a casual sexual partner, 34.4 percent used a condom the last time they had sexual intercourse with a casual sexual partner.

\section{Religiosity and likelihood of having a casual sexual partner}

Not all the respondents reported to have had sexual intercourse with a casual sexual partner. Accordingly, the main objectives were to 1) examine the role of one's level of religiosity in choosing to have sex with a casual sexual partner and 2) subsequently examine whether or not they would use condom as a form of protection.

Table 2 (see Annex 2 to the present document) shows the relationship between religiosity and the likelihood of having a casual sexual partner. The results indicate that in models 1, 2, 3 and 4 those who attended religious meetings for more than once a week were less likely to have a casual sexual partner compared to those who attended occasionally (model $1=41.9 \%$; model $2=$ $38.5 \%$; model $3=40.0 \%$ and model $4=36.1 \%$ ) and the results were statistically significant (p < 0.001). However, there were no statistically significant differences in the likelihood of having a casual sexual partner among those who attended religious meetings once a week, every two weeks, once a month and those who attended occasionally.

Further, sex, place of residence, ethnicity and marital status significantly predicted the likelihood of having a casual sexual partner. In models 2, 3 and 4, males have higher odds of having a casual sexual partner compared to females (2.3 times, 2.2 times, and 2.4 times respectively). In

model 4, those who lived in urban areas had also $36.7 \%$ higher odds of having a casual sexual partner compared to those living in rural areas. In addition, while the Ewe, Guan and those classified as other Ghanaians had higher odds $(47.1 \%, 77.6 \%$ and $60.8 \%$ respectively) of having a casual sexual partner, the Mole-Dagbani (32.4\%) had lower odds of having a casual sexual partner compared to the Akan. The results also show that those who were never married (41.8\%) and those who were formerly married $(51.5 \%)$ had higher odds of having a casual sexual partner compared to those who were currently married.

\section{Relationship between religiosity and condom use with a casual sexual partner}

The relationship between religiosity and condom use with a casual sexual partner is shown in Table 3 (see Annex 3 to the present document). The analysis here focuses on respondents who reported to have had sexual intercourse with a casual sexual partner. Those who had no casual sexual partner prior to the survey were not included in the analysis because the objective was to 
examine how a person's level of religiosity may affect the use of condoms during a sexual intercourse with a casual sexual partner. Therefore, it was considered not meaningful to assess a person's likelihood or otherwise of using condoms with a non- existent casual sexual partner. The stepwise binary logistic regression results indicate that sex and education influenced the effect of religiosity most when all the socio-demographic variables were added one after the other. Hence, the results for these two variables (i.e., sex and education) are presented separately in models 2 and 3 respectively in Table 3 .

In model 1, those who attended religious meetings once a month had 2.2 times higher odds of using a condom with a casual sexual partner compared to those who attended occasionally, and this was statistically significant $(\mathrm{p}<0.05)$. However, when the socio-demographic factors were controlled for in models 2, 3, and 4, religiosity was not statistically significant in explaining condom use with a casual sexual partner.

Further, age, sex, level of education, place of residence, ethnicity and marital status were statistically significant related to condom use (Table 3). It can be observed from Table 3 that males had 5.7 times higher odds of using a condom with a casual sexual partner compared to females. Compared to those who had no formal education, those with Middle/JHS (2.5 times), Secondary/SHS (2.3 times), Vocational (3.2 times), and Higher (1.96 times) education had higher odds of using a condom with a casual sexual partner. With regard to age group, the odds of using condom with a casual sexual partner was lower among those who were 40-44 years $(53.8 \%)$ and $45-49$ years $(63.6 \%)$ compared to those who were 12-19 years. Compared to those in the rural areas, urban residents had 57.8 percent higher odds of using a condom with a casual sexual partner. Also, the Ga-Dagme had 82.9 percent higher odds of using a condom with a casual sexual partner than the Akan. It was also observed that respondents who were formerly married had a higher likelihood of condom use with a casual sexual partner compared to those who were currently married.

\section{Discussion}

From the analysis, it is quite clear that the respondents who were highly religious (attending religious activities more than once a week) were less likely to have a casual sexual partner compared to those who attended religious activities only occasionally. On the other hand, the results among those who were relatively less religious did not suggest any statistically significant 
relationship with the likelihood of having a casual sexual partner. This lends support to the earlier observation that most conventional religions, such as Christianity to which the majority of the respondents belong, discourage extra-marital sexual activities, including adultery (Penhollow, Young and Denny 2005). Such sexual activities are often experienced with a casual partner. This suggests that the teaching against adultery and sexual promiscuity by most religions is adhered to mainly by the most religious people, which is revealed by the frequency of their attendance at religious activities. Relatedly, it suggests that people who abide by their religious teachings tend to avoid pre- or extra-marital sexual activity, which is often experienced with a casual sexual partner.

The finding that males are more likely to have a casual sexual partner may be explained by the traditional and widespread view that it is "acceptable" for males to engage in extra-marital sex while it is not acceptable for females to do so. This is what Awusabo-Asare et al. (1999) describe as a double standard for sexual relations in Ghanaian society - a standard that results from unequal gender relations. On the other hand, a higher likelihood of casual sexual partnership among urban residents compared to rural dwellers could be due to the openness of urban residents to modern lifestyles that permit sex networking, especially when residents do not have their sexual partners living with them or are never married, Moreover, traditional norms regarding fidelity and avoidance of casual sex may not be adhered to in urban areas as much as in rural areas. Casual sex may also be more rampant in the anonymous environment that urban settings often provide. In rural communities, where all of the residents know each other, causal sexual activity may be frowned upon. Similarly, the never married and formerly married people may not be in stable sexual relationships and may be more likely to engage in casual sexual activity. In contrast, currently married people may see themselves as being in stable unions and may be less likely to report casual sexual activity or practice it to a lesser extent. Thus it may not necessarily mean that married people are less likely to engage in casual sexual activity than unmarried people; rather, it is possible that married people report it less because they may be seen as not being faithful to their regular sexual partners.

The results further showed that when controlling for other socio-economic and demographic factors there was no strong statistically significant relationship between religiosity and condom use. With no other independent variables in the model, only those who attended religious activities once a month had higher likelihood of using a condom with a casual sexual partner 
compared to others who attended occasionally ( $\mathrm{p}<0.05$ ). Once, other variables were controlled, this effect disappeared. Thus, level of religiosity did not show a consistent effect on the likelihood of using condoms in a sexual activity that involves a casual sexual partner. Even though many studies have shown that those who are religious have lower condom use (Rostosky et al. 2004; Lefkowitz et al. 2010; Chimbindi et al. 2010; Zaleski and Schiaffino 2000) our study did not show any statistically significant relationship when other socioeconomic and demographic factors were controlled for. According to Zaleski and Schiaffino (2000), even though religious identification may protect students from sexual risk-taking, those who are religious are less likely to use a condom. Consequently, religiosity may connote a risk factor for unsafe sex among those who are sexually active.

Our study is similar to that of Lefkowitz et al., (2010) which showed no statistically significant relationship between religiosity and condom use. This may indicate that sexual behavior in Ghana may be largely driven by factors other than religiosity. Another explanation may be that there is a high level of integration among people of different levels of religiosity in Ghana and those who behave differently when it comes to condom use.

This study shows that condom use was mainly predicted by sex, level of education and type of place of residence (i.e., rural or urban). These three variables were the highest contributors to explaining the probability of condom use among the respondents. As was shown in model 4, when all the socioeconomic and demographic characteristics of respondents were added to their religiosity, the individual's sex and level of education emerged as the highest explanatory factors for the likelihood of condom use with a casual sexual partner. A similar result was shown in model 3 when both sex and education were added to religiosity as independent variables. While in all the models, males showed a higher likelihood of using condoms than females during casual sexual activity, level of education did not show consistency by educational hierarchy. What was clear, however, was that the likelihood of condom use during casual sexual activity increased with educational attainment (i.e., the more educated a person is, the more he/she will use a condom during causal sexual activities).

Studies have shown that the socioeconomic status of individuals (e.g., education) is a major determinant of condom use. David-Gore et al., (2011) showed that people living in households with lower levels of wealth were more likely to inconsistently use and never use a condom compared to those in the wealthiest households. Other studies have also shown similar findings 
(Hargreaves et al. 2002, 2007; Lopman et al. 2007; Madise et al. 2007; Weiser et al. 2007). Our study shows that education is significantly related to condom use. This is consistent with findings by Largard et al. (2001) in the cities of Yaounde (in Cameroon) and Cotonou (in the Republic of Benin). A plausible explanation for this finding is that those who have a relatively higher level of education may have more knowledge about the need to protect oneself against sexually transmitted infections (e.g. HIV) during casual sexual activity and may be better placed to afford and access a condom. They are probably more aware of the health risks associated with not using a condom. Education is also a marker of socioeconomic status. Thus, people with a high level of education may have more ability to negotiate safe sex through condom use.

As has been earlier noted, our study showed that condom use was significantly higher among males than females. Studies have shown that women may not be able to protect themselves even if they want to because of sociocultural constraints or because of economic circumstances or inequalities, such as gender relations that characterize the sexual relations between men and women (Adedimeji et al. 2008). Thus, women with more economic resources may have higher ability to negotiate safe sex by use of a condom (David-Gore et al. 2011; Hallman 2004; Chimbindi et al, 2010). Also, low socioeconomic status has more consistent negative effects on female than male sexual behaviors (Hallman 2004). Another plausible explanation for why men recorded higher likelihood of condom use than women in our study is that condoms are a maledetermined method; it is usually the man who determines whether or not a condom is used (Chimbindi et al. 2010). Hence, in the context of HIV and AIDS, empowering women to adopt protective behavior independent of men or sexual partners could lead to better condomuse-negotiation skills among women, which would help prevent HIV transmission (Adedimeji et al. 2008; Gage 1998; Estrin 1999; Slap 2003; Chimbindi et al. 2010).

Condom use was significantly higher among urban residents compared to those in rural areas. This is similar to a study conducted in Nigeria (Oyediran et al. 2011). Urban residents are more aware of the intrinsic value of condom use compared to those in rural areas. Thus, urban area residents tend to be more sexually experienced and more likely to use condoms than their counterparts in rural areas (Oyediran et al. 2011). It is noteworthy that in Ghana levels of education vary between urban and rural areas. Rural residents are more disadvantaged and tend to have limited knowledge about risks associated with non-condom use during casual sex.

Our study revealed that those who are 40-44 years and 45-49 years had lower odds of condom use 
compared to adolescents within 15-19 years. This may be as a result of condom promotion programs in Ghana that target adolescents and compel them to engage in safe sex. Studies have shown that young people are inquisitive and more likely to be apprehensive of STIs and unwanted pregnancy, leading to higher odds of condom use (Haque and Soonthomdhada 2009). Furthermore, condom use was higher among those who were formerly married compared to others who were currently married. This may be due to the misconception that condom should be used only with commercial sex workers. In the view of some people, insistence on condom use particularly in stable marital unions may connote lack of trust (Haque and Soonthomdhada 2009).

\section{Conclusion}

This study demonstrates that condom use remains low in Ghana. There was no significant relationship between religiosity and condom use. Condom use was, however, significantly related with level of education, place of residence, sex, ethnicity, age and marital status. There is need for more programs to promote formal education in order to increase condom use in Ghana. Gender relations and residential status are factors associated with condom use and have been persistent despite the focus on them in anti-HIV campaigns. Innovative ways of addressing these barriers to condom use are necessary, apart from efforts at improving the formal educational status of women. 


\section{References}

Adedimeji, A., N. Heard, O. Odutolu and O. Omololu. (2008). Social factors, social support and condom use behaviour among young urban slum inhabitants in Southwest Nigeria. East African Journal of Public Health 5(3):215-222.

Anarfi, J.K. and A.A. Gyasi-Gyamera. (2014). Religiosity and Attitudes towards Homosexuality: Views of Ghanaian University Students. In Ralph L. Piedmont and Andrew Village (eds). Research in the Social Scientific Study of Religion. Volume 25.

Atiemo, A.O. (2013). Religion and the Inculturation of Human Rights in Ghana. Bloomsbury, London. pp. 173-201.

Awusabo-Asare, A.M. Abane, J.K. Anarfi and Delali M. Badasu (1999). 'All Die be Die': Obstacles to Change in the Face of HIV Infection in Ghana. Health Transition Review, pp.125-131.

Böhmig, C. (2010). There is Somebody in Heaven Who Takes care of Tou!: Nursing and the Religiosity on a Hospital Ward in Ghana. Medische Antropology. 22(1):47-61.

Brewster, K.L., E.C. Cooksey, D.K. Guilkey and R.R. Rindfuss. (1998). The changing impact of religion on the sexual contraceptive behavior of adolescent women in the United States. Journal of Marriage and the Family, 60, 494-504

Chimbindi N.Z., N. McGrath, K. Herbst, K.S. Tint and M. Newell. (2010). Sociodemographic determinants of condom use among sexually active young adults in rural kwaZulu-Natal, South Africa. The Open AIDS Journal, 4:88-95.

Davidoff-Gore A, N. Luke and S. Wawire. (2011). Dimensions of poverty and inconsistent condom use among youth in urban Kenya. AIDS Care, 23(10):1282-1290.

Estrin, D. (1999). In Ghana, young men's condom use is linked to lack of barriers, perceived susceptibility to HIV infection. International Family Planning Perspectives. 25:106-107.

Ghana AIDS Commission (2015). Country AIDS Response Progress Report-Ghana. www.unaids.org/sites/default/files/documents/GHA_narrative_report. Accessed on $28^{\text {th }}$ August 2016.

Ghana Statistical Service, Ghana Health Service, and ICF Macro (2009). Ghana Demographic and Health Survey, 2008. Accra, Ghana: GSS, GHS, and ICF Macro.

Hallman K. (2004). Socioeconomic disadvantage and unsafe sexual behaviors among young women and men in South Africa. Population Council, 190:1-48. Available at: http://www.popcouncil.org/uploads/pdfs/wp/190.pdf. Accessed on 14 October, 2014.

Haque M.R. and A. Soonthorndhada. (2009). Risk perception and condom-use among Thai youths: findings from Kanchanaburi Demographic Surveillance System site in Thailand. 
Journal of Health, Population and Nutrition, 27(6):772-783.

Hargreaves, J.R., L.A. Morison, J. Chege, N. Rutenburg, M. Kahindo, H.A. Weiss and A. Buve. (2002). Socioeconomic status and risk of HIV infection in an urban population in Kenya. Tropical Medicine and International Health, 7, 793802. doi: 10.1046/j.13653156.2002.00943.x

Kwankye, S.O. (2007). Adolescent Sexuality and Reproductive Health in Ghana: Some Results from a Survey of Cape Coast and Mankrong. In C.J. Mba and S.O. Kwankye (eds.) Population, Health and Development in Ghana: Attaining the Millennium Development Goals. Accra: Sub-Saharan Publishers.

Ladin L., K. Engle, C. Jackson, and J.D. Brown, (2006). Early adolescents' cognitive susceptibility to initiating sexual intercourse. Perspectives on Sexual and Reproductive Health, 38, 97- 105.

Largarde E., M. Carael, J.R. Glynn, L. Kanhonou, S. Abega, M. Kahindo, R. Musonda, B. Auvert and A. Buve. (2001). Educational level is associated with condom use within nonspousal partnership in four cities of sub-Saharan Africa. AIDS, 15:1399-1408.

Lefkowitz, E.S., M.M. Gillen, C.L. Shearer and T.L. Boone. (2010). Religiosity, sexual behaviors and sexual attitudes during emerging adulthood. The Journal of Sex Research, 41(2):150-159.

Lopman, B., C.J. Lewis, P.L. Nyamukapa, S. Mushati, P.L. Chandiwana and S. Gregson. (2007). HIV incidence and poverty in Manicaland, Zimbabwe: Is HIV becoming a disease of the poor? AIDS, 21(Suppl. 21), S57S66. doi: 10.1097/01.aids.0000300536.82354.52

Madise, N., E. Zulu and J. Ciera. (2007). Is poverty a driver for risky sexual behaviour? Evidence from national surveys of adolescents in four African countries. African Journal of Reproductive Health, 11(3), 8398. doi: 10.2307/25549733.

Meier, A. (2003). Adolescents' transition to first intercourse, religiosity, and attitudes about sex. Social Forces, 81, 1031-1052.

Nabila, J.S., C. Fayorsey and M. Pappoe. (1997). Youth and Reproductive Health in Africa: Assessment of Reproductive Needs in Ghana. Population Impact Project (PIP): Accra.

Oyediran, K.A., O.I. Feyisetan and T. Akpan. (2011). Predictors of condom-use among young never- married males in Nigeria. Journal of Health, Population and Nutrition, 29(3):273-285.

Pinhollow, T., M. Young and G. Denny. (2005). The Impact of Religiosity on the Sexual Behaviors of College Students. American Journal of Health Education. March/April, Volume 36, No. 2. pp. 75- 83.

Rizzi, E. (2004). Religiousness and sexual ethics. In G. Dalla Zuanna \& C. Crisafulli (Eds.). Sexual behaviour of Italian students. Messina, Italy: University of Messina, pp. 249- 263. 
Regnerus, M. D. (2007). Forbidden fruit: Sex and religion in the lives of American teenagers. New York: Oxford University Press.

Rostosky, S. S., B.L. Wilcox, M.L.C. Wright and B.A. Randall. (2004). The impact of religiosity on adolescent sexual behavior. Journal of Adolescent Research, 19: 677- 697.

Weiser, S.D., K. Leiter, D.R. Bangsberg, L.M. Butler, F. Percy-de Korte, Z. Hlanze N. Phaladze, V. Iacopino and M. Heisler. (2007). Food insufficiency is associated with high-risk sexual behavior among women in Botswana and Swaziland. PLoS Medicine, 4, 15891598. doi: 10.1371/journal.pmed.0040260.

United Nations. (2015). Trends in Contraceptive Use Worldwide. United Nations, New York. www.un.org/en/development/desa/population/publications. Accessed on $28^{\text {th }}$ August 2016.

Zaleski, E.H. and K.M. Schiaffino. (2000). Religiosity and sexual risk-taking behaviour during the transition to college. Journal of Adolescence. 23: 223- 227. 
Table 1 Background Characteristics of Respondents

\begin{tabular}{|c|c|c|}
\hline Background characteristics & Number $=4168$ & Percentage \\
\hline \multicolumn{3}{|l|}{ Sex } \\
\hline Female & 2959 & 71.99 \\
\hline Male & 1209 & 29.01 \\
\hline \multicolumn{3}{|l|}{ Level of education } \\
\hline No education & 1126 & 27.02 \\
\hline Primary & 779 & 18.69 \\
\hline Middle/JHS & 1383 & 33.18 \\
\hline Secondary/SHS & 451 & 10.82 \\
\hline Vocational/Technical & 101 & 2.42 \\
\hline Higher & 328 & 7.87 \\
\hline \multicolumn{3}{|l|}{ Age Group } \\
\hline $12-19$ & 329 & 7.89 \\
\hline $20-24$ & 730 & 17.51 \\
\hline $25-29$ & 770 & 18.47 \\
\hline $30-34$ & 731 & 17.54 \\
\hline $35-39$ & 667 & 16.00 \\
\hline $40-44$ & 527 & 12.64 \\
\hline $45-49$ & 414 & 9.93 \\
\hline \multicolumn{3}{|l|}{ Place of residence } \\
\hline Rural & 2085 & 50.02 \\
\hline Urban & 2083 & 49.98 \\
\hline \multicolumn{3}{|l|}{ Religion } \\
\hline Catholic & 629 & 15.09 \\
\hline Protestant/Anglican & 818 & 19.63 \\
\hline Charismatic/Pentecostal & 1361 & 32.65 \\
\hline Other Christian & 410 & 9.84 \\
\hline Muslim & 742 & 17.80 \\
\hline Traditional/spiritualist/Other & 206 & 5.94 \\
\hline \multicolumn{3}{|l|}{ Ethnic group } \\
\hline Akan & 1802 & 43.23 \\
\hline Ga-dagme & 284 & 6.81 \\
\hline Ewe & 576 & 13.82 \\
\hline Mole-dagbani & 831 & 19.94 \\
\hline Guan & 156 & 3.74 \\
\hline Other Ghanaian & 519 & 12.45 \\
\hline \multicolumn{3}{|l|}{ Marital status } \\
\hline Never married & 889 & 21.33 \\
\hline Currently married & 2603 & 62.45 \\
\hline living together & 342 & 8.21 \\
\hline
\end{tabular}


Separated

Divorced

Widowed

\section{Religiosity}

Occasionally

Once a month

Every two weeks

Once a week

More than once a week

\section{Casual Partnership}

No casual sexual partner

Had casual sexual partner

Condom use with casual sexual partner

Did not use condom

566

Note: RC refers to reference category in subsequent logistic regression analysis.

Source: Barriers to Condom Use in Ghana Study, 2011/2012 
Table 2 Binary logistic regression showing the relationship between religiosity and likelihood of having a casual sexual partner

\begin{tabular}{|c|c|c|c|c|}
\hline \multirow[b]{2}{*}{ Background characteristics } & \multicolumn{4}{|c|}{ Odds ratio (standard error) } \\
\hline & Model 1 & Model 2 & Model 3 & Model 4 \\
\hline \multicolumn{5}{|l|}{ Religiosity $(\mathrm{RC}=$ occasionally) } \\
\hline Once a month & $.34(.03)$ & $1.46(.38)$ & $1.44(.38)$ & $1.50(.41)$ \\
\hline Every two weeks & $.74(.22)$ & $.80(.24)$ & $.79(.24)$ & $.80(.25)$ \\
\hline Once a week & $.91(.11)$ & $.97(.11)$ & $.95(.11)$ & $1.05(.13)$ \\
\hline More than once a week & $.58(.07)^{* * *}$ & $.62(.08)^{* * *}$ & $.60(.07)^{* * *}$ & $.64(.08)^{* * *}$ \\
\hline \multicolumn{5}{|l|}{ Sex $(R C=$ female $)$} \\
\hline Male & & $2.26(.18)^{* * *}$ & $2.20(.18)^{* * *}$ & $2.42(.21)^{* * *}$ \\
\hline \multicolumn{5}{|c|}{ Level of education $(\mathrm{RC}=$ no education $)$} \\
\hline Primary & & & $1.15(.14)$ & $1.04(.14)$ \\
\hline Middle/JHS & & & $1.21(.13)$ & $1.02(.12)$ \\
\hline Secondary/SHS & & & $1.22(.17)$ & $.90(.15)$ \\
\hline Vocational/Technical & & & $1.49(.37)$ & $1.10(.29)$ \\
\hline Higher & & & $1.29(.20)$ & $.95(.17)$ \\
\hline \multicolumn{5}{|l|}{ Age Group $(\mathrm{RC}=12-19)$} \\
\hline $20-24$ & & & & $.88(.15)$ \\
\hline $25-29$ & & & & $.90(.16)$ \\
\hline $30-34$ & & & & $.91(.17)$ \\
\hline $35-39$ & & & & $.75(.15)$ \\
\hline $40-44$ & & & & $.84(.17)$ \\
\hline $45-49$ & & & & $.78(.17)$ \\
\hline \multicolumn{5}{|l|}{ Place of residence $(\mathrm{RC}=$ rural $)$} \\
\hline Urban & & & & $1.37(.12)^{* * *}$ \\
\hline \multicolumn{5}{|l|}{ Religion $(\mathrm{RC}=$ Catholic) } \\
\hline Protestant/Anglican & & & & $.90(.12)$ \\
\hline Charismatic/Pentecostal & & & & $.94(.12)$ \\
\hline Other Christian & & & & $.92(.15)$ \\
\hline Muslim & & & & $.88(.14)$ \\
\hline Traditional/spiritualist/ & & & & $1.38(.28)$ \\
\hline Other & & & & $1.50(.20)$ \\
\hline \multicolumn{5}{|l|}{ Ethnic group $(\mathbf{R C}=$ Akan $)$} \\
\hline Ga-Dagme & & & & $1.31(.21)$ \\
\hline Ewe & & & & $1.47(.17)^{* *}$ \\
\hline Mole-Dagbani & & & & $.68(.10)^{* *}$ \\
\hline Guan & & & & $1.78(.36)^{* *}$ \\
\hline Other Ghanaian & & & & $1.61(.23)^{* *}$ \\
\hline
\end{tabular}


Never married

$1.42(.18)^{* *}$

living together

$.94(.15)$

Formerly married

$1.52(.05)^{* * *}$

Model Fit

Log likelihood

McFadden's R-squared

$-2103.97$

$-2053.38$

$-2050.46$

$-2000.17$

.010

.034

.035

.060

Significance of F-statistic

.000

.000

.3163

.000

for nested

$* * * P<.001 * * P<.01 * P<.05 ; R C$ - Reference Category; ( )

Standard error Source: Barriers to Condom Use in Ghana Study, 2011/2012 
Table 3 Binary logistic regression showing the relationship between religiosity and condom use with casual sexual partner

\begin{tabular}{|c|c|c|c|c|}
\hline \multirow[b]{2}{*}{ Background characteristics } & \multicolumn{4}{|c|}{ Odds ratio (standard error) } \\
\hline & Model 1 & Model 2 & Model 3 & Model 4 \\
\hline \multicolumn{5}{|l|}{ Religiosity $(\mathrm{RC}=$ occasionally) } \\
\hline Once a month & $2.18(.84)^{*}$ & $1.96(.78)$ & $1.97(.80)$ & $1.94(.82)$ \\
\hline Every two weeks & $.59(.36)$ & $.68(.43)$ & $.64(.41)$ & $.60(.39)$ \\
\hline Once a week & $.94(.20)$ & $1.07(.23)$ & $.99(.22)$ & $1.04(.23)$ \\
\hline More than once a week & $.85(.18)$ & $.98(.21)$ & $.91(.20)$ & $1.05(.24)$ \\
\hline \multicolumn{5}{|l|}{$\operatorname{Sex}(\mathrm{RC}=$ female $)$} \\
\hline Male & & $5.20(.72) * * *$ & $4.54(.65) * * *$ & $5.70(.88)^{* * *}$ \\
\hline \multicolumn{5}{|c|}{ Level of education $(\mathrm{RC}=$ no education $)$} \\
\hline Primary & & & $1.91(.56)^{*}$ & $1.44(.44)$ \\
\hline Middle/JHS & & & $3.71(.89)^{* * *}$ & $2.49(.66)^{* *}$ \\
\hline Secondary/SHS & & & $4.42(1.20)^{* * *}$ & $2.33(.71)^{* *}$ \\
\hline Vocational/Technical & & & $5.53(2.14)^{* * *}$ & $3.16(1.31)^{* *}$ \\
\hline Higher & & & $3.57(1.05)^{* * *}$ & $1.96(.65)^{*}$ \\
\hline \multicolumn{5}{|l|}{ Age Group $(\mathrm{RC}=12-19)$} \\
\hline $20-24$ & & & & $0.84(.23)$ \\
\hline $25-29$ & & & & $1.03(.29)$ \\
\hline $30-34$ & & & & $0.77(.25)$ \\
\hline $35-39$ & & & & $0.55(.19)$ \\
\hline $40-44$ & & & & $0.46(.17)^{*}$ \\
\hline $45-49$ & & & & $0.36(.15)^{*}$ \\
\hline \multicolumn{5}{|l|}{ Place of residence $(\mathrm{RC}=$ rural $)$} \\
\hline Urban & & & & $1.58(.25)^{* *}$ \\
\hline \multicolumn{5}{|l|}{ Religion $(\mathrm{RC}=$ Catholic $)$} \\
\hline Protestant/Anglican & & & & $0.91(.21)$ \\
\hline Charismatic/Pentecostal & & & & $0.94(.21)$ \\
\hline Other Christian & & & & $0.59(.18)$ \\
\hline Muslim & & & & $0.69(.19)$ \\
\hline Traditional/spiritualist/ & & & & $0.66(.30)$ \\
\hline \multirow{2}{*}{\multicolumn{5}{|c|}{ Ethnic group ( $\mathrm{RC}=$ Akan $)$}} \\
\hline & & & & \\
\hline Ga-Dagme & & & & $1.83(.44)^{*}$ \\
\hline Ewe & & & & $1.42(.29)$ \\
\hline Mole-dagbani & & & & $1.30(.34)$ \\
\hline Guan & & & & $.96(.42)$ \\
\hline Other Ghanaian & & & & $1.02(.30)$ \\
\hline \multicolumn{5}{|c|}{ Marital status $(\mathrm{RC}=$ currently married $)$} \\
\hline Never married & & & & $1.44(.30)$ \\
\hline
\end{tabular}


living together

Formerly married

Model Fit

Log likelihood

McFadden's R-squared

$-917.36$

$-845.09$

$-818.09$

.112

.000

.150

Significance of F-statistic for nested models

***P<.001 **P<.01 *P<.05; RC-Reference Category; ( )

Standard error Source: Barriers to Condom Use in Ghana Study, 2011/2012
$1.38(.36)$

$1.96(.58)^{*}$

$-788.29$

.144

.000 